\title{
Public Engagement on Climate and Health in Museums and Participa- tory Dialogues may Foster Behavior Change
}

\author{
Kathryn A Stofer ${ }^{1}$, Lisa Lundgren², Betty A Dunckel ${ }^{3}$, Vaughan James ${ }^{4}$, Makenna Lange ${ }^{1}$ and Janice Krieger ${ }^{4}$
}

${ }^{1}$ Department of Agricultural Education and Communication, University of Florida; ${ }^{2}$ College of Natural Resources, North Carolina State University; ${ }^{3}$ Florida Museum of

Natural History; ${ }^{4}$ College of Journalism and Communications, University of Florida

Keywords: Public Engagement, Behavior Change, Community Action, Participatory Design, Dialogue

Publication Date: June 17, 2019

DOI: https://doi.org/10.15695/jstem/v2i1.10

\begin{abstract}
As scientific knowledge grows and the planet's human population makes unprecedented changes, decision-making places more and more demands on the everyday democratic participant. Yet efforts to help the public acquire and make use of evidence-based information fall short. We present preliminary comparisons of three participatory design models of public engagement with science designed to encourage community action rather than just raise awareness in participants on local public health issues impacted by climate change. We collected survey data at two in-person community-based participatory dialogues and a museum exhibit and presented but received no surveys from televised versions of the participatory dialogues. Results indicated that behavior change was indeed salient to participants. Actions participants plan to take included sharing what they learned, contacting legislators, and direct conservation efforts. Future research should study whether participants undertake planned actions and do so in groups rather than as individuals.
\end{abstract}

\section{INTRODUCTION}

As the body of scientific knowledge grows and the planet's human population makes unprecedented changes, the decisions to be made place more and more demands on the everyday public community participant. Indeed, Pidgeon and Fischhoff (2011) indicate that evidence-based public communications regarding climate change are critically important, as climate science is a swelling and complex field. Other reports focus on the importance of developing effective strategies for public engagement with science, such as those created by the Center for Advancement of Informal Science Education (McCallie et al., 2009) and the National Informal STEM Education Network (Bell et al., 2018). Yet efforts to help the public acquire and make use of evidence-based information are still falling short (Pew Research Center, 2015b; Volmert et al., 2013a; Volmert et al., 2013b), and even well-informed people tend to rely instead on motivated reasoning that allows them to preserve a worldview that makes them feel good or absolves them of responsibility (Kahan, 2012; van der Linden et al., 2015). At the same time, public trust in science, at least on particular issues, may be waning in the United States (Pew Research Center, 2015a; 'Public Praises Science; Scientists Fault
Public, Media,' 2009). Moreover, the everyday person may overestimate their own expertise (Scharrer et al., 2016) or feel overwhelmed in the face of large global issues such as climate change (Frumkin et al., 2008), reducing even further their reliance on evidence for decision-making or even their likelihood of taking action at all in the face of despair. In the end, knowledge gain for a situation may be irrelevant if it does not lead to changes in behavior.

While more and more organizations in the informal, nonformal, or free-choice science learning (Stofer, 2015) realm are entering the landscape with the mission of engaging their audiences with evidence for decision-making (American Association for the Advancement of Science, 2016; Davies et al., 2009), many still focus on raising awareness through one-way information dissemination (Christiano and Neimand, 2017), though awareness alone is unlikely to motivate decision-making or lead to behavior change (Carolan, 2008; Christiano and Neimand, 2017; McKenzie-Mohr, 2013). Although interactivity has been documented in science communication exhibits and events (e.g. Heath et al., 2005; Kamolpattana et al., 2015; Kato-Nitta et al., 2017), organizations that pursue more engaged discussion models may struggle 
to overcome years of entrenched styles of information delivery (Dijkstra, 2017; Lafrenière and Cox, 2012; Mizumachi et al., 2011), not only from within but also from the scientists they recruit to participate and public audiences themselves. Some have argued that museums can act as mediators for climate science communication (Salazar, 2015), or that climate change communication in formal education settings can be augmented through participatory dialogue (Busch and Osbourne, 2014). Internationally, museums and other informal science institutions have contributed to public understanding of climate science, creating nine principles for promoting action and understanding of climate change (Cameron et al., 2013). While these principles provide guidance for how such institutions should respond to climate change, they do not illustrate ways to overcome deficit models of communication. This study seeks to identify ways to overcome such models in the realm of climate change communication.

Furthermore, high-engagement events also face challenges when it comes to scaling up participation, reaching audiences over longer time periods and larger geographic regions (Lövbrand et al., 2011). Whereas some research exists into knowledge increases associated with science cafés (e.g. Navid and Einsidel, 2012), such studies are focused solely on medical health (Ahmed et al., 2014), one type of participatory dialogue, shows little evidence of knowledge increase but promising signs of emotional engagement (Lafrenière and Cox, 2012), which may be a precursor to behavior change. Finally, individual action on issues, especially complex global problems such as climate change, may need to give way to larger actions, meaning engagement and behavior change must start to focus on community-level and more proactive solutions beyond simply changing lightbulbs in personal residences (Ordner, 2017).

Particularly for climate change, the global scale can make it difficult for people to see how the changes affect them (Popovich et al., 2017). Localizing the problem and tying it to problems that are more obviously personally relevant, such as health, may help to overcome these hurdles. Therefore, designing engagement efforts with the input of the audiences which organizations aim to reach is crucial (Alender, 2016; Bhattacharyya et al., 2017; Lengwiler, 2009; Rai, 2003).

At the time of the study, climate change was, and remains, a political topic, with discussions centered on the 'realness' of climate change despite overwhelming evidence that climate change is real, occurring, and damaging (Cook et al., 2016). In our region in particular, models suggest increased periods of drought followed by intense rain, and warmer temperatures overall leading to more extreme temperature events that threaten health; in our part of the state, we are not prone to problems of sea level rise that will plague coastal areas (Melillo et al., 2014).

We undertook this research program to design and com- pare explicitly three methods of public engagement on climate change as it affects human health. Our hope was to address issues of engagement through participatory design, increase scale in time and space, and promote behavior change. We also hoped to reach audiences beyond the traditional museum visitor and science café participant in the United States and collect demographic data on participants in these settings as the few existing studies on science cafés, for example, do not typically report demographics.

The first context is a museum panel exhibit, traditionally allowing a large audience to engage over time but not promoting discussion or behavior change, described in further detail below. The other two models were an in-person panel and audience discussion followed by small group discussion and an edited, delayed television broadcast of the participatory dialogue. Using mixed-method research (Creswell and Clark, 2007), we report here the main preliminary findings for motivating behavior change. As such, we had the following research questions:

(1) What are the characteristics of general science interest, trust in scientists, and levels of concern about our specific topics for our event participants?

(2) Does involving audience in selecting topics lead to higher engagement of audiences, as evidenced through self-report of interactions at the events?

(3) Can we motivate group-level action through our three models of public engagement?

\section{METHOD}

Data Collection. Our research setting was a suburban region in the southeastern United States in late 2016. In particular, the study was conducted in a city with a population of approximately 150,000 people, which included a museum and university. In the region, the majority of residents identified as White (57.2\%) followed by those who identified as Black $(21.7 \%)$ and those who identified as Hispanic (10.2\%). Over 90 percent of residents were United States citizens, and the median age for residents was 24 years old ("Data USA," n.d.).

We recruited adult participants through targeted advertisements in local and regional online and print media. Participants did not necessarily participate in all models, although some who engaged via social media before the live participatory dialogues may have participated subsequently in the live community-based 'participatory dialogues.' We developed these through intercept interviews with museum visitors and surveys of local science café participants to determine topics (Lundgren et al., 2019). Based on these methods, we focused on public health concerns about air quality (participatory dialogue \#1) and water quality (participatory dialogue \#2). To compare emotional engagement, knowl- 
edge gain, and change in behavioral intent, we used methods appropriate for each context, including observations, online, and paper surveys. We will briefly describe the methods for each context before describing the results collated across the contexts.

For the three contexts of the participatory dialogues (live, streamcast, and broadcast), we developed surveys in Qualtrics using some validated questions from other surveys. These surveys included behavioral change questions that asked participants to comment on time frames in which they would (or would not) change their behavior (Jayaratne et al., 2005). For example, one of the questions asked participants if they intended to carpool within a month or six months after attending the program, with the options to indicate instead that they have already been carpooling for less than one month or for six months or more, as well as whether they do not intend at all to carpool. We gauged emotional engagement after the participatory dialogues through a polar question with a text box allowing for participants to elaborate on their response as to whether each of the three panelists generated emotion in the participant (Lafrenière and Cox, 2012). Participants also reported their ways of expected and actual participation in the event and their motivation for attending. We also asked before and after the event participants' 1) trust in scientists, 2) concern that climate change would personally harm them, 3) concern about climate change overall for the topic discussed, 4) knowledge of group or community actions to affect climate change, 5) perception of their community's ability to impact climate change, and 6) knowledge about the specific public health and climate change topics under discussion (Hmielowski, et al., 2014). Finally, in addition to standard demographic questions, participants also self-reported their scientific expertise and science interest (C. Gibbs, personal communication, Sept. 12, 2016), as well as whether they discuss climate change with friends, family members, or others. For full survey, see Supplemental Material.

We provided hyperlinks to the surveys at the end of the programs for the streamcasts and broadcasts. In-person participants could complete surveys online or on paper. In-person participants completed two surveys, one immediately after the participatory dialogue itself, the second after an informal dinner discussion with all of the panelists, which the attendees were welcome to join. We also invited participants both online and in person to discuss via social media with hashtags and social media links posted throughout the programs.

The last context was a museum exhibit created by applying participatory design principles (Simon, 2010) and featuring six panels (three per topic) about the same topics as the participatory dialogues. A panel is wall-mounted and typically contains primarily text and photos with few interactive elements. We created an exhibit of six panels, mounted ap- proximately 11 " off the floor, measuring 40 " in height and displayed three per wall for a total width per wall of 140". The panels included two interactives: an air quality monitor and a board on which visitors could record their action plans regarding public health and climate change. The panels were in a large open gallery at the front of the museum and not thematically connected to other surrounding exhibits or materials; however, the same walls had been used for several rotating panel exhibits over the previous few years on other aspects of climate change such as local sea-level rise. Details on the content of our six panels with added interactive elements for visitors to report their planned actions are described in (Lundgren et al., 2019). We had planned to use the same survey as offered to the participatory dialogue participants. However, after two sessions, we observed visitors only attending to the exhibit for approximately 15 seconds. This low attendance factor led us to modify our protocol to ask three open-ended non-polar questions as recommended by Seidman (2013) for every other visitor/visitor group who attended to the exhibit for greater than 15 seconds. Questions were: What drew you to the exhibit?; what was your major takeaway from the exhibit?; and what action do you plan to take after visiting the exhibit? For more detail on the development of the museum exhibit and the subsequent research on the visitor responses via interviews and comment cards with action plans see Lundgren et al. (2019).

Data Analysis. We used mixed data analysis methods including content analysis of intercept interviews, exhibit comment cards, social media comments, and open-ended survey questions (Saldaña, 2016). The second author used Microsoft Excel and GraphPad Prism to produce descriptive statistics on the interest, expertise, emotion, knowledge, ability to make an impact, and participation preference questions from the surveys. For questions asked about knowledge and levels of concern before and after the events, the second author compared individual participant respondents' changes in a paired fashion though we did not run t-tests or non-parametric equivalents. The second author produced descriptive and inferential statistics of post-participatory dialogue and post-discussion closed-ended survey questions for behavior change using Dunn's multiple comparisons in GraphPad. Content analysis involved the first and second authors independently coding segments of data, resolving discrepancies together to establish the codebook (Hsieh and Shannon, 2005). Then the second author coded the majority of the data.

Broadcast recordings of community-based participatory dialogues. We received no responses from the broadcast participatory dialogues to the surveys or social media. Therefore, we cannot analyse the ways in which these contexts led to behavior change concerning climate change and public health. We comment further in the discussion. 


\section{Live in-person community-based participatory dialogues.}

We analysed surveys collected from the in-person participatory dialogues using content analysis for the open-ended questions and descriptive and inferential statistics for the Likert-type questions. We received 24 surveys $(\mathrm{n}=12$ per participatory dialogue) for the immediate post-participatory dialogue, and 17 following the dinner discussion $(\mathrm{n}=9$ air quality, $\mathrm{n}=8$ water quality). We first discuss questions on reasons for attending the event, background in science, expectations of the event, and trust in science to characterize our participants. Then we focus on participants' responses to survey questions that concerned behavior change, with participant names and identities masked by using alphanumeric codes, for example, ADWQP2 for After Discussion Water Quality Participant 2, and ADAQP3 for After Discussion Air Quality Participant 3.

Museum exhibit. The first and second authors took notes for all interviews $(n=13)$ and categorized and tallied these notes by question. We collected comment cards from the exhibit at the end of each visiting day in late $2016(n=151)$. Comment cards were open-response, allowing visitors to describe three components: what aspects of the world they wanted to protect, by what action, with whom (see Figure 1). Comment cards were accessible to any visitor during the museum's visiting hours. Using content analysis, the first and second authors coded the comment cards, focusing on the types of actions visitors indicated they would take concerning public health and climate change.

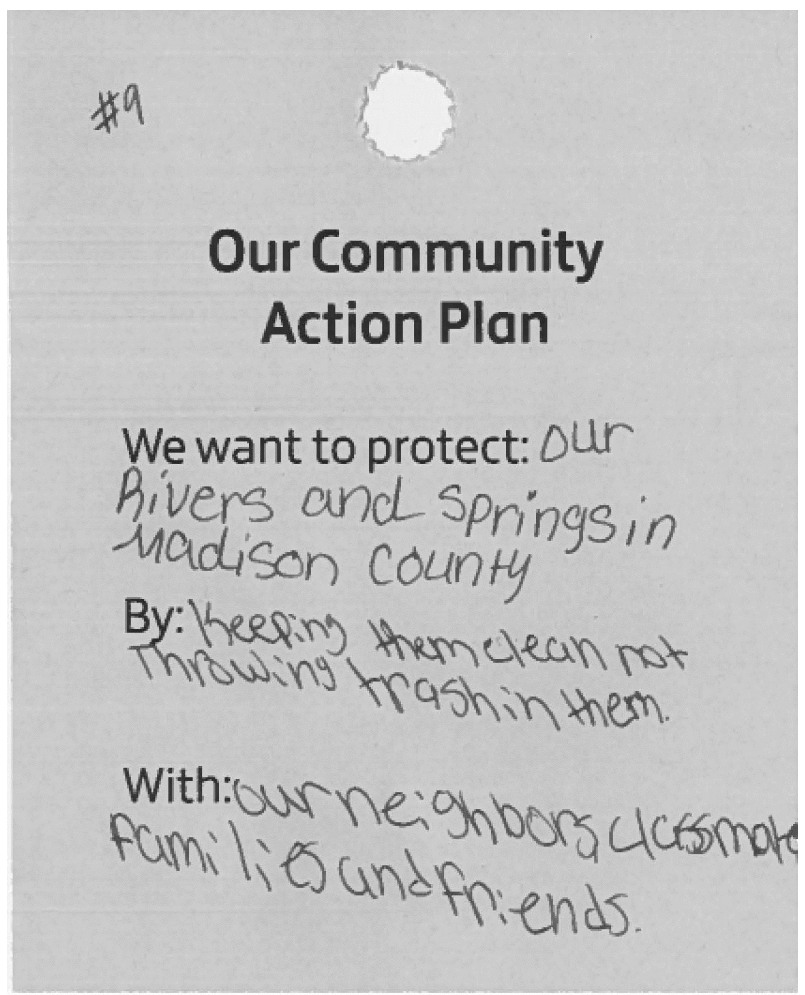

Figure 1. Example exhibit visitor comment card with group action plans.

\section{RESULTS}

Live in-person community-based participatory dialogues. Psychographics. To begin to characterize the beliefs and attitudes of people who might attend science café or similar dialogue events, we asked participants about their interest in science, motivation for attending the event, and trust in scientists. For the air quality event, the majority of participants were split in their expertise among 'I am a scientist by profession' $(n=4)$, 'I am a science enthusiast' $(n=4)$, and 'I don't think of myself as a science enthusiast, but I do enjoy mixing informal learning and socializing' $(n=3)$. For water quality, participants were split among 'I am a scientist by profession' ( $\mathrm{n}=5)$, 'I am a science enthusiast' $(\mathrm{n}=5)$, and 'I have a science degree, but don't work in the sciences as my profession' $(\mathrm{n}=4)$ (see Figure 2 ).

For each event, the specific topic was by far the most popular motivation for attending, with eight and nine of the participants selecting this as their motivation for coming to the air quality and water quality events, respectively. 'The general opportunity to connect with science' was the selection of two participants for each event. For the air quality event, two participants each also selected 'the speakers, who I do not know, but whose research interests me,' and 'speakers who I know' (see Figure 3). Participants had also discussed climate change with family, friends, and co-workers more often than not prior to attending the events, with about $25 \%$ at each event discussing the topic 'a lot' with all three groups (see Figure 4).

When considering trustworthiness of scientists, 10 of 11 participants for the air quality event and 10 of 11 for the water quality event came in to the events with moderately to extremely high trust in scientists. Only two participants in the air quality event increased their level of trust in scientists through the event; the other participants' levels did not change (see Figure 5).

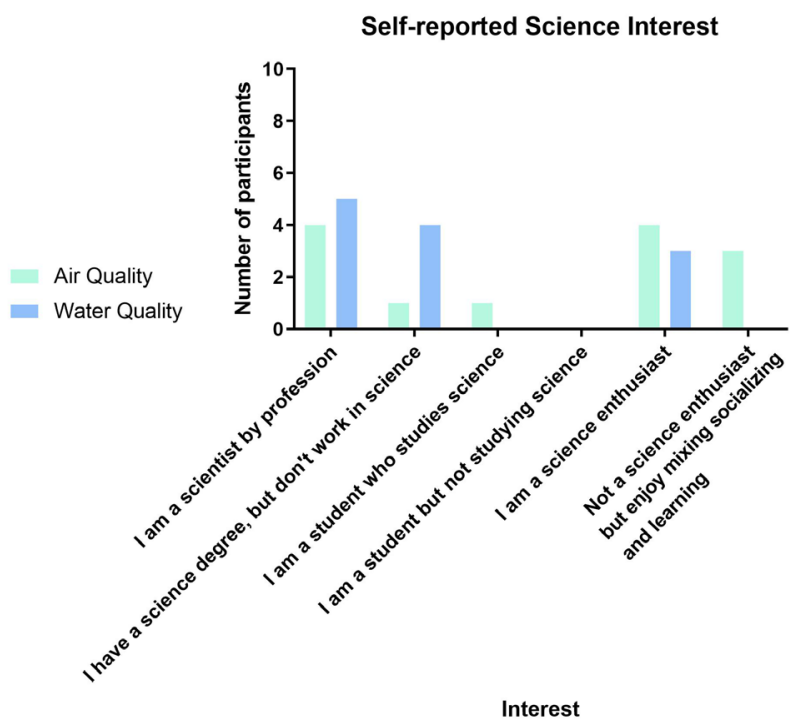

Figure 2. Participatory dialogue participant self-reported science interest 
Expected participation. We also were interested in whether participants contributed questions to the participatory dialogue before the event and how they participated during the events. Before the air quality event, we received only one

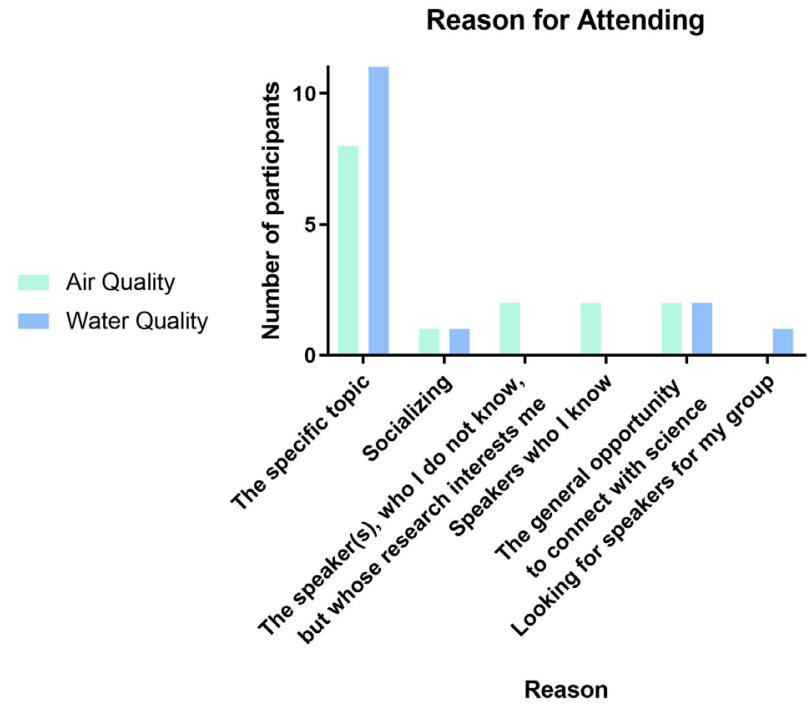

Figure 3. Participatory dialogue participant reason for attending

\section{How often have discussed climate change with others previously}
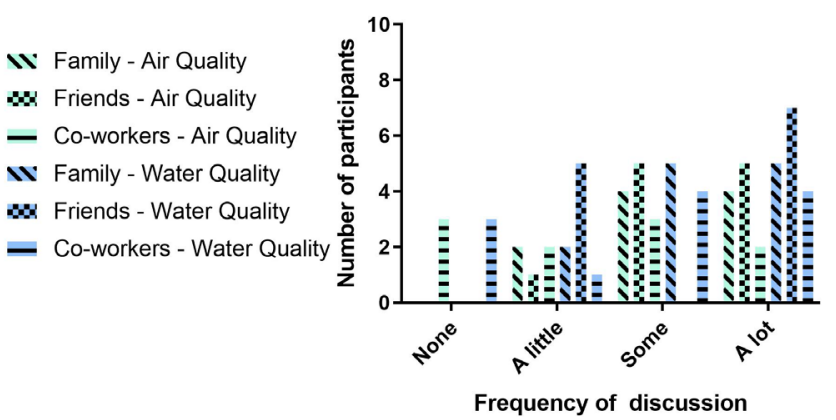

Figure 4. Participatory dialogue participant level of discussion of climate change with others.
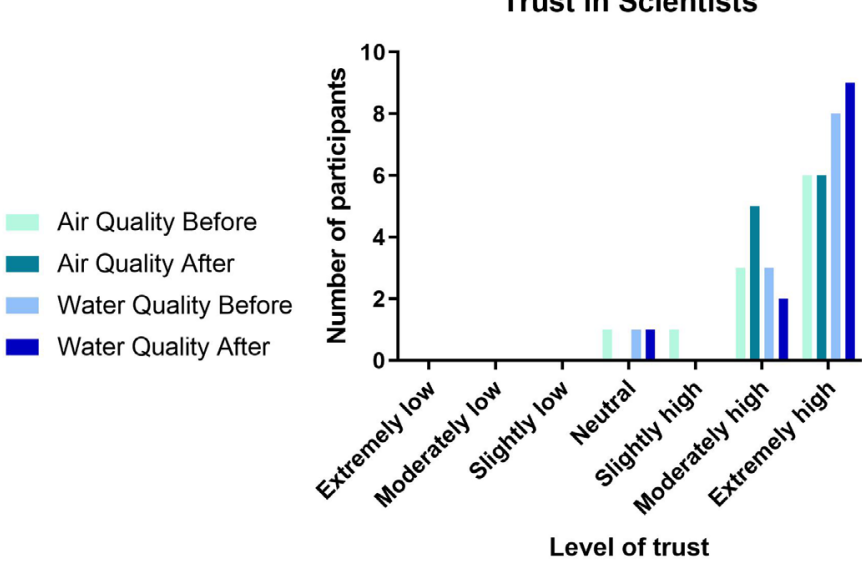

Figure 5. Participatory dialogue participant trust in scientists. question through our solicitations in advertisements, and one participant indicated in the survey that they had submitted a question. We received three questions for the water quality participatory dialogue. For the air quality event, two participants $(18 \%)$ indicated they expected mostly to be given information at the event, two (18\%) indicated they expected a chance to voice their own views and discuss with the community, and seven (64\%) indicated they expected to receive information and have a chance to ask questions. For water quality, the results were more evenly distributed: four (36\%) expected mostly to receive information, and three each $(27 \%$ each) expected to voice their own views and discuss with community members or receive information with a chance to ask questions; one participant did not answer (see Figure 6).

In the air quality event, seven (64\%) participants indicated afterwards that they had only received information, and only two each (18\% each) both received information and asked questions or voiced their own views and discussed with the community. For the water quality event, four $(36 \%)$ indicated they only received information, five $(45 \%)$ received information and asked questions, two (18\%) said they voiced their own views and discussed with others, and one did not answer about their actual participation in the event (see Figure 6).

Knowledge. Participants reported their knowledge about the particular topics of the participatory dialogues before and after the event. Before the air quality event, participants reported between 'slightly low' $(\mathrm{n}=1)$ and 'moderately high' $(n=4)$ levels of knowledge of climate change's effects on allergies (see Figure 7). Before the water quality event, participants reported between 'neutral' $(\mathrm{n}=1)$ and 'extremely high' $(\mathrm{n}=1)$ levels of knowledge of climate change's effects on water quality (see Figure 8). After the event, the distri-

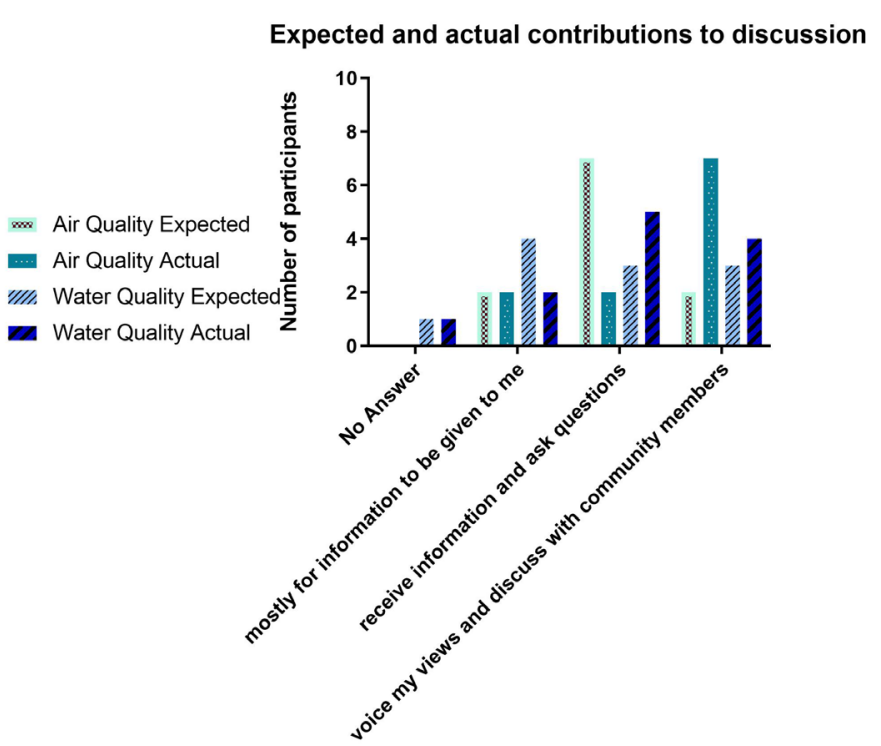

Figure 6. Participatory dialogue participant expected and actual contributions to event discussion 
butions of participants for both events shifted more toward the 'extremely high' end of the scale. For both air quality and water quality after the event, participants all ranked their knowledge as 'slightly high' or higher, with more people in the higher levels of knowledge overall. Despite the initial high level, for the air quality event eight of 11 (72\%) participants reported increased knowledge after the event, and six of $11(54 \%)$ reported increases after the water quality participatory dialogue. Two participants reported decreased levels after the water quality event.

We also asked about knowledge of group or community actions that could affect climate change related to those topics. While we did not define these for participants, the authors conceptualize these as actions taken with more than

\section{Level of knowledge about climate change effects on allergies}

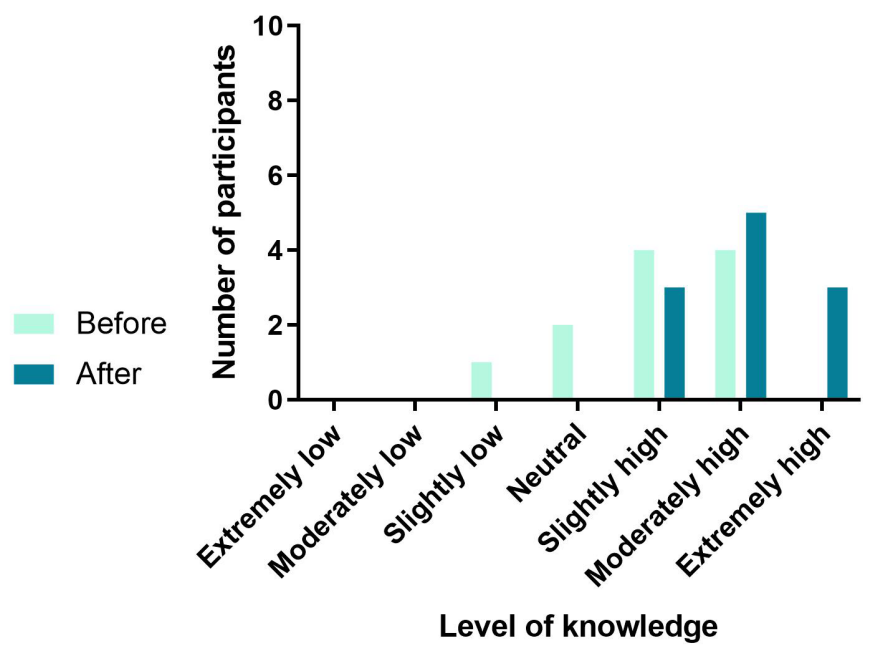

Figure 7. Participatory dialogue participant level of knowledge about climate change effects on allergies

\section{Level of knowledge about climate change effects on water qualtiy}

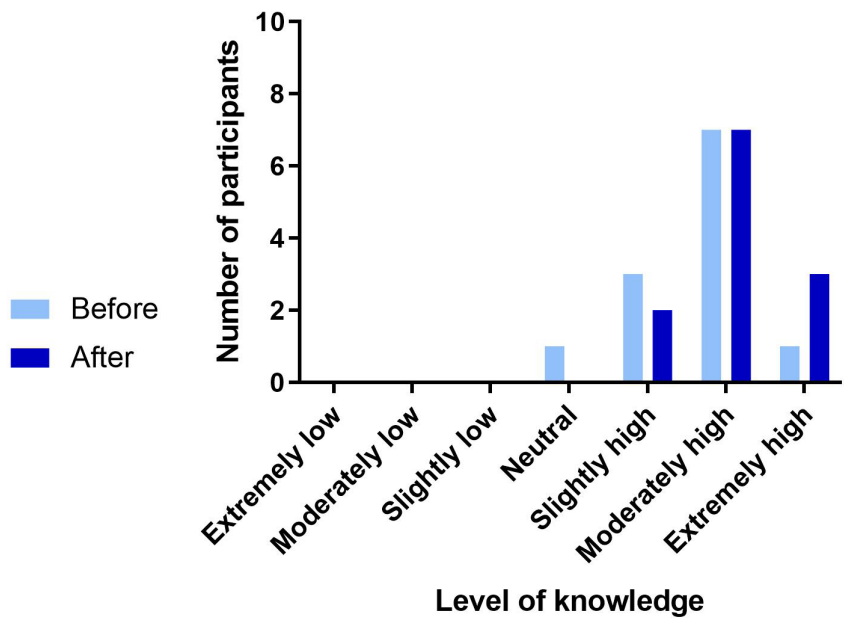

Figure 8. Participatory dialogue participant level of knowledge about climate change effects on water quality. one person involved; see results for examples from the exhibit. When asked about how much they knew about group or community actions to affect climate change locally, before the event, participants in the air quality participatory dialogue reported slightly high $(\mathrm{n}=2)$, moderately $(\mathrm{n}=$ $5)$, or extremely high $(n=3)$ levels of knowledge, with the exception of one participant who reported extremely low knowledge. After the event, all participants reported slightly high or higher. Water quality event participants reported more mixed levels, with one participant each at extremely low, slightly low, and neutral responses. Five, three, and one participant reported slightly, moderately, and extremely high knowledge, respectively. After the event, the water quality participants also all reported slightly high or higher levels of knowledge of group actions that can impact climate change (see Figure 9).

Levels of concern. For the participatory dialogues, we asked participants before and after the event about their level of concern about climate change, level of certainty that climate change would harm them personally in their lifetime, and ability of their community to make a difference on climate change related to the specific participatory dialogue topics. For level of concern about climate change, before the event, five of 11 respondents (45\%) already had 'extremely high' levels of concern about climate change; these did not change after the event. However, four (36\%) of the remaining six participants, all of whom started out with 'slightly high' or 'moderately high' levels of concern increased their concern during the course of the event. For water quality, 10 of 11 participants started out at 'moderately high' or 'extremely high' levels of concern before the event; only one 'moderately high' level changed to 'extremely high' during the event (see Figure 10).

When asked about their level of certainty climate change would harm them personally in their lifetimes, only one participant in either participatory dialogue (air quality), responded with a neutral answer before the event. The remain-

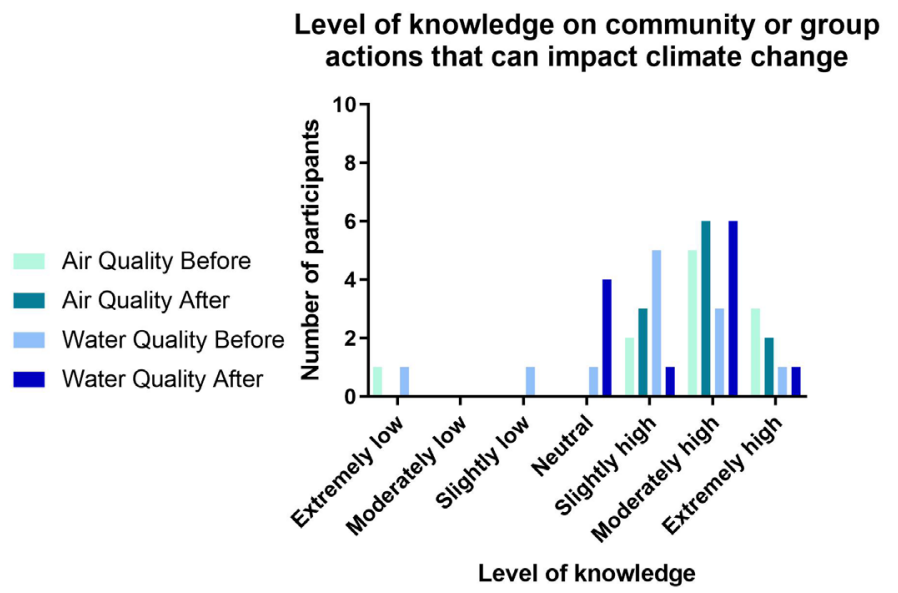

Figure 9. Participatory dialogue participant level of knowledge on community or group actions that can impact climate change. 
ing participants were all slightly high $(\mathrm{n}=6)$, moderately high $(n=5)$, or extremely high $(n=11)$ levels of concern. After the event, participants shifted to more concerned overall (see Figure 11).

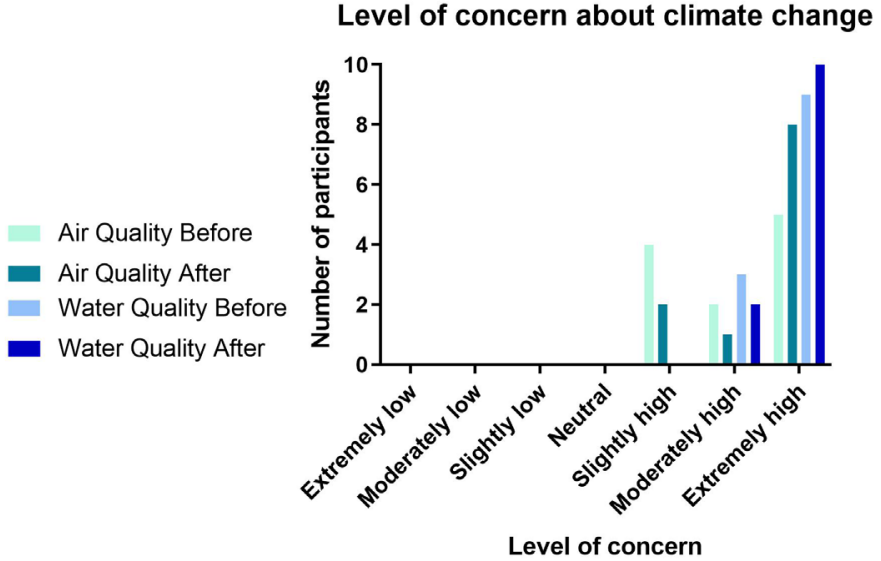

Figure 10. Participatory dialogue participant level of concern about climate change.

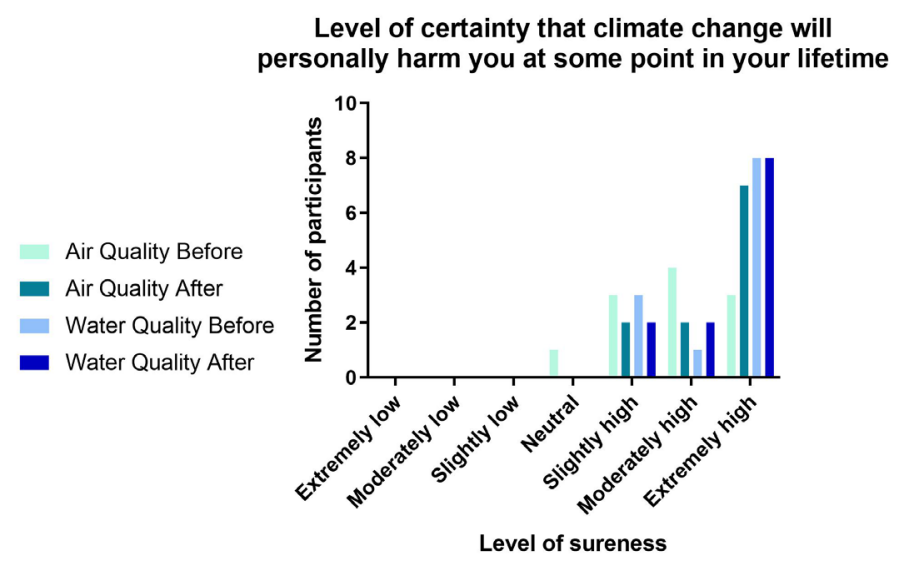

Figure 11. Participatory dialogue participant level of certainty of climate change personal harm.

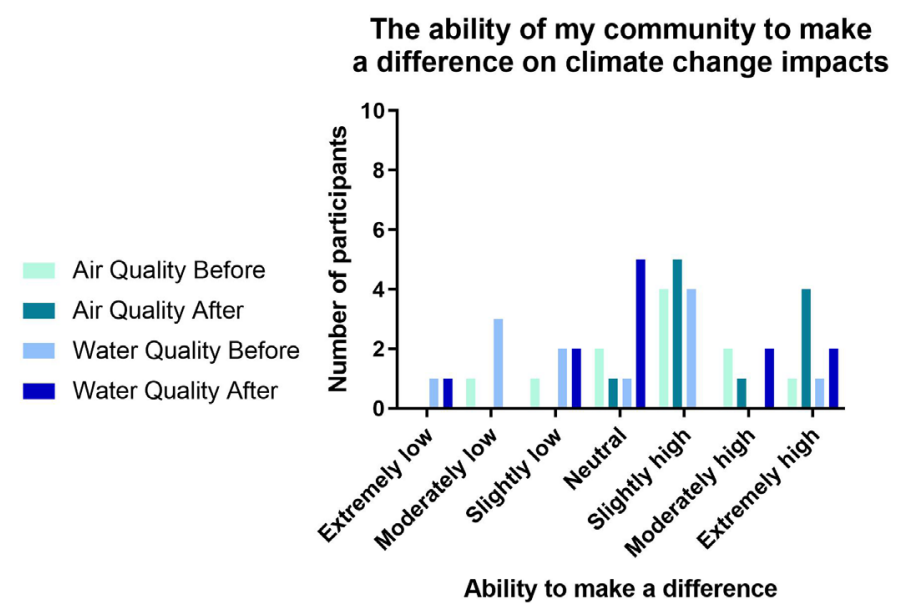

Figure 12. Participatory dialogue participant confidence in community to make a difference on climate change.
The last level of concern question covered the ability of the local community to make a difference on climate change on the topics at hand. Overall, participants were less confident about the ability of their communities to make a difference than they were knowledgeable of group actions that can make a difference. Before both events, the majority of participants responded 'slightly high' or lower $(n=8$ for air quality, $n=9$ for water quality). After the air quality event, participants were more confident overall, with ten participants in air quality reporting 'slightly high' or higher levels of confidence. Water quality participants were also more confident than before, but for this group, 'neutral' was the most frequent $(\mathrm{n}=5)$ response after the event, one step lower on the scale than for the air quality group (see Figure 12).

Emotions evoked by panelists. To determine whether the events evoked emotions, we asked participants about emotions evoked by the individual presenters. For the air quality event, nine of 11 participants indicated they experienced emotions when listening to each of the two scientific experts, and 10 of 11 agreed they experienced emotions when listening to our community climate action partner. For the water quality event, 10 of 11 participants said one scientist evoked emotions, while only seven out of 11 felt the second scientist evoked emotions. Based on the words of the community climate action partner, nine of 11 participants experienced emotions.

Behavior change intentions. To determine if the community-based participatory dialogues affected participant interaction with information about making a plan of action concerning public health and climate change, researchers asked about such plans of action. Survey responses revealed that participants most often indicated that they planned to contact their political representatives about climate change and that they had no plans to carpool to work or school (see Figure 13). There were no significant differences between groups who attended each participatory dialogue or who responded to each category.

Analysis of participant responses revealed that the

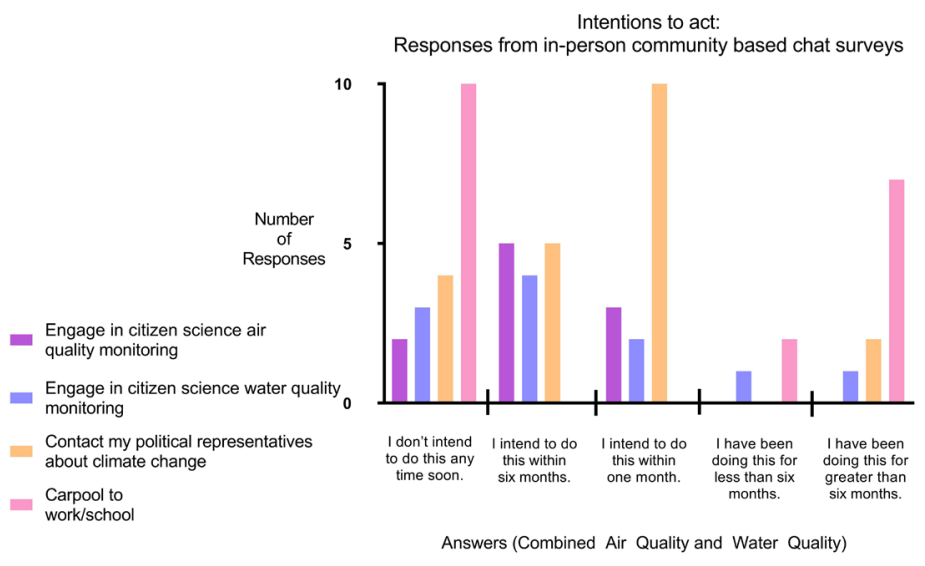

Figure 13. Participatory dialogue participant intention to change behavior. 
post-participatory dialogue group discussions had some influence on their plans of action regarding general issues, including intent to participate in a group action such as citizen science (Bonney et al., 2009) in order to contribute to the existing data on regional climate issues, or take community action to mitigate climate change, such as by promoting public transit (See Figure 14).

Those who attended the water quality participatory dia-

Did the group discussion influence your plan of action regarding the following issues?
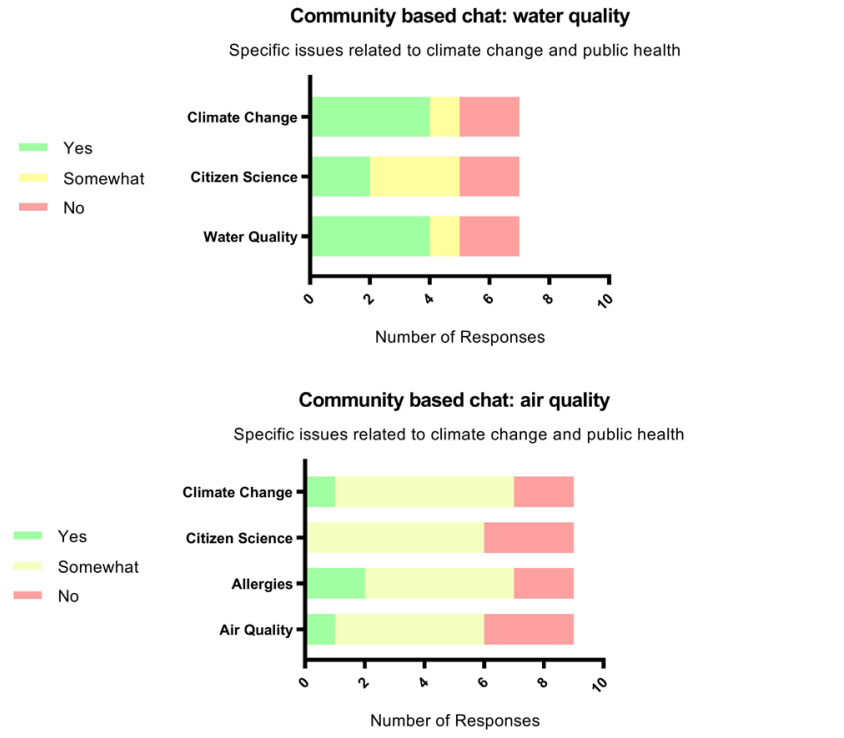

Figure 14. Participatory dialogue participant influence of after-dinner discussion on intent to change behavior.

logue indicated that the group discussion did influence their plan of action, responding 'yes' $(\mathrm{n}=4)$ more often than 'no' $(\mathrm{n}=2)$ and 'somewhat' $(\mathrm{n}=1)$ on the survey. The participants who attended the air quality participatory dialogue also indicated the group discussion influenced their action plans, but they were less changed than the water quality participants, indicating 'somewhat' $(\mathrm{n}=5)$ more often than 'yes' $(\mathrm{n}=1)$ when indicating whether the discussion affected their action plans regarding air quality. However, when subjected to statistical analyses, there were no significant differences between the groups.

We asked participants to describe these changes further in an open-ended survey response. When queried about this, one participant wrote, 'I plan to learn more about climate change and water quality' (Participant ADWQP2). Another participant wrote that the group discussion influenced them by giving them, 'encouragement to continue sharing information!' (ADAQP3). Another participant responded that the group discussion gave them 'talking points for discussion with people who don't accept climate change' (ADWQP6). Furthermore, one participant (ADAQP3) was exhilarated by the community-based participatory dialogues, as they were a place that buoyed their enthusiasm for sharing information, although they did not indicate whether said information concerned public health and climate change.

\section{Remote and delayed broadcast participatory dialogues.}

For the televised and streamcast versions, we received no responses to our surveys or requests to interact via social media. We do know that the televised versions, which aired in February 2017 in a five-part series of similar public health forums, did reach viewers. The water quality program received a Nielsen share of 0.5 or one-half percent of the viewing audience, for a total of approximately 500 households in our market (The Nielsen Company, 2014). The air quality and allergy program reached approximately 1200 households.

Museum exhibit. For the museum exhibit context, we applied the same concepts concerning plans of actions to align with the participatory dialogues. For the intercept interviews and exhibit comment cards $(\mathrm{N}=164)$, iterative collaborative inductive coding sessions resulted in four overarching categories. For this paper, we focus on one of the four categories: actions related to public health and climate change that communities could take, which had 43 responses (26\%). Subcategories within this category included: limiting litter or pollution $(\mathrm{n}=10)$, education and communication $(\mathrm{n}=7)$, taking political action $(n=6)$, and car use $(n=4)$. Other actions related to public health and climate change which did not have enough responses to merit individual categories were classified as 'uncategorized' $(n=16)$. Four participants indicated not having a plan of action even when explicitly asked for one. Full analysis of the museum exhibit interaction is discussed in Lundgren et al. (2019).

Responses on the comment cards included action plans that ranged broadly, from local actions aimed at protecting local water resources such as springs, to national actions such as protecting National Parks from fracking. Within the most prevalent subcategory, limiting litter, even the definition of 'community' was broad-ranging. Community took the form of 'the whole world,' 'community groups,' and 'friends and family,' indicating that although those who filled out the comment cards had a concrete idea about litter, community was an amorphous topic.

\section{DISCUSSION}

We began our investigation with three main research questions: what are our participant characteristics, does participatory design lead to engagement, and can we motivate group-level action? For all three questions, the contexts in which we studied engagement by public audiences with climate change and public health yielded limited and mixed but promising results. Our attempts to study broadcast audiences were unsuccessful in that we were unable to collect 
survey responses from people who might have viewed the participatory dialogues these ways, although we had high numbers of viewers based on Nielsen ratings. We postulate that this is due to the small scale of our pilot as well as to the time-bound nature of our survey: we asked potential participants to respond immediately following the broadcast of a one-shot event. Our exhibit attempted to move beyond the generalized, amorphous view of climate change that is often displayed in museums when tackling this complex subject (Cameron, 2010), and our results indicate preliminary success on this front.

For the first and second questions, we were able to characterize our in-person audiences for the live events, though our audiences were small. Overall, they were primarily motivated to attend by the specific topic, and about half were scientists by profession, though a nearly equal number described themselves as 'science enthusiasts.' They had high levels of trust in science before and after the events, and many had discussed climate change with family, friends, and/or co-workers at least occasionally before attending the event. This seems to indicate preliminary success for our second question about attracting new audiences who are not already extensively engaging on the topic, though not those who are already trusting of science. While we could not characterize their backgrounds, the large number of households reported as viewing the broadcasts suggest this is a model to investigate further for scaling the reach of in-person participatory dialogues.

Further for our second question about engagement, only about one-quarter of attendees expected before the event to have a chance to voice their own views, though two-thirds reported expecting to be able to discuss with others. Audience discussion is a central tenet of Dallas' (1999) original Café Scientifique model. The remainder of participants expected mostly that information would be given to them. We suspect this is indicative of broader expectations for participation in learning events, both in school and out-of-school, where the traditional model is of an expert lecture to share information. Slightly more than half, however, reported after the event that they had in fact asked questions or voiced their own views and discussed with community members; this occurred a bit more at the water quality event than the air quality event. The initial expectation level could be due to either the novelty of the format for some participants, limitations in advertising the discussion-based nature, or ingrained expectations of these types of events. Further research should attempt to increase the numbers of participants asked about their expected participation and tease apart these differences in the source of the expectations. The actual level of participation was slightly lower than the expected level in both events. A lower number of people asking questions could be due to either the somewhat more formal appearance of the events due to the television production or the thoroughness of the questions asked and materials covered by the presenters. However, the lack of reports of people discussing with other community members is distressing, given the deliberate format at the end of the evening after the initial panel. Our video production of the event did capture discussions of the nature we were expecting, on the topic at hand. Therefore, the lack of participant reports of this may be the result of limitations in our survey, which can be addressed in future research.

The events affected participants' level of concern and knowledge about climate change somewhat differently. The air quality participants had more mixed concern at the beginning of the event, though all were on the concerned side of neutral, but a larger number of those who were not already extremely highly concerned increased their concern through the events. The events, therefore, may not have increased the levels of concern for many people who are already highly aware of the potential impacts of climate change. Further research with participants who are less concerned about climate change could determine whether this panel and discussion-style event can increase concern amongst some of those populations. The air quality participants also had lower levels of knowledge before the event, but more participants reported increased knowledge after the event than the water quality event. This could be due to differences in participants' knowledge before the event, differences in overall awareness of climate change's effects on the individual topics, or the content of the discussions themselves. As noted, two participants reported decreased levels of knowledge after the water quality events, which is likely more reflective of our methods of pre- and post-event surveys than actual declines in knowledge. A retrospective pre-post survey instrument could address this presumed anomaly. For water quality, the event did not generally change participants' opinions that climate change would harm them personally, while it did increase that concern of about a third of the air quality event participants. The events both increased participants' knowledge of group actions to affect climate change and their perceptions that their communities could affect climate change.

The speakers did provoke emotion in the vast majority of participants. However, the events did not generally increase trust in scientists. These were not explicit goals of our events, so we did not ask the speakers to speak in any way to either evoke emotion or particularly promote trust. Future research could examine the effectiveness of such strategies. Rather, we confirm findings from previous research that these events can evoke emotion (Lafrenière and Cox, 2012), which may be necessary for action (Moser, 2007), and add to the literature suggesting that participants may come in with a high level of trust. This may mean that these events could serve as ways to mobilize people to action, specifically making them aware of their high levels of trust and asking them 
to leverage that with members of their community who may trust them instead of scientists whom they may not know, as suggested by cultural cognition (Kahan, 2008) and other similar theories (Bolsen et al., 2015) of democratic participatory behavior.

For our third research questions, our analysis of in-person and exhibit audiences indicate that people are motivated by these contexts to intend to change their behavior and to take action in the face of climate change, regardless of the specific topic. In the context of the participatory dialogues, participants indicated actions they could take, though these were broad in scope. Specifically, exemplar responses indicate that the participatory dialogue participants engaged in varied discussions at dinner including those that concerned climate change and water quality as well as climate change denial. This adds to the overall literature about how to design science café-style interactions to move beyond a lecture-based format for information dissemination.

While the experiences instilled a generalized sense of action and were reported simply as behavioral intentions, these plans are a step in the right direction and can serve as stepping stones for further development of exhibits of this type and future directions of research on true behavior change. We were surprised at the breadth of topics reported for targets of action especially in the exhibits, as we created the panels using iterative prototyping with visitors and focused on localized issues including water quality of springs and climate-change-driven increase in seasonal allergies. Combined with qualitative results from the exhibit panels, described in detail in Lundgren et al. (2019), we suggest that when we specifically set out to tie content in exhibits and events to actions, participants indeed report intentions to change their behaviors and take action after participation.

One limitation inherent to this study is though many of our survey questions came from validated sources, our survey did not comprise a validated survey itself. However, we sought concurrent validity by using the same questions across multiple contexts. We also reviewed the questions with experts for face validity. Furthermore, the small number of participants makes it difficult to generalize. The lack of quantitative data from the exhibits, broadcasts, and streamcast community-based participatory dialogues also complicates the comparison that we set out to do with the other models. The localized content focus prevents some transferability, but in general, our results and model of local content in a generalizable behavior change motivation framework suggest an initial description of engagement in two of our three contexts. Therefore, we suggest behavior change intention be incorporated into the study of a variety of models of public engagement.

Responses from the participants in the participatory dialogues themselves and the small-group discussion after the participatory dialogues suggest that engaging groups of people with different expertise and interests can positively influence behavior change intentions, not just awareness of issues. The same could be said for people who engaged with the traditional, low-interaction museum panel exhibit. Collecting contact information from these participants and following up with them in six months or a year after the events should be a next step in future studies. Direct or unobtrusive observation at museums could also provide more information on the use of the exhibit panels and particularly who chooses to use comment cards. Furthermore, extensive surveys with the exhibit visitors who choose to engage with the exhibit for longer periods of time could yield more data about visitor action plans concerning climate change.

For future design of these events and research, we suggest leveraging partnerships with other community groups who are not already visitors to your museum or attendees at your participatory dialogues and using existing social media communities who are not engaged with you for online recruitment as well. For example, reach out to neighbourhood organizations for communities, especially rural audiences, who do not generally visit, when collecting data to choose your topic and prototype your exhibit components. Take your prototypes to them instead of asking them to come to you. This can double as advertising for your eventual exhibit and events. We tried to reach out beyond our already-attentive audience to break down barriers to participation but did not leave sufficient time to build a brand new audience, especially for engaging people through social media. We do not feel the study design itself needs changing, though continual improvements to exhibit engagement may make it more possible to offer a more extensive survey that will be more directly comparable to results from the dialogue events. Finally, to collect data from broadcast viewers, work with the broadcast station, in our case, a local public channel, to determine how best to engage viewers in responding, perhaps through mailings before and after the broadcast, or more fundraising-style appeals where a host breaks in every so often to remind viewers of the research associated and the request for their research participation.

\section{CONCLUSION}

Our first contribution is to begin to describe the audiences at science-café style events in terms of both cognitive and affective self-report measures. Next, we offer preliminary evidence on levels of engagement through participation in the events. Finally, we find that events and exhibits may be able to motivate behavior change when the models are explicitly designed to do so.

Many forms of public engagement with science focus on awareness messaging to ensure that the broader public knows about the severity of climate change. Instead of fixating on such awareness messaging or continuing to promote 
only individual action, we set out to motivate group level actions concerning climate change as objective knowledge does not in itself lead to behavior change (Christiano and Neimand, 2017; McKenzie-Mohr, 2013). We sought to accomplish our goal through an innovative pilot program that reached audiences in a variety of contexts, including a museum exhibit and online, televised, and in-person community-based participatory dialogues. Despite low numbers of participants, we found evidence to suggest the promise for more engagement and outcomes of behavior change when these goals are explicitly built into exhibits and programs rather than just assumed to occur, for example, when holding events in public spaces and sharing information without linking it to action. To continue to examine the potential to motivate behavior change surrounding climate change, we suggest implementing public engagement events that encourage discussion between community members, as well as creating museum exhibits that focus on issues relevant to local populations.

\section{ASSOCIATED CONTENT}

Supplemental content can be found at https://ufdc.ufl. edu/IR00010878/00001

\section{AUTHOR INFORMATION Corresponding Author}

Kathryn A. Stofer. PhD. University of Florida. PO Box 110540. Gainesville, FL 32611. stofer@ufl.edu. (352) 2733690.

\section{Author Contributions}

The manuscript was written through contributions of all authors. All authors have given approval to the final version of the manuscript.

\section{FUNDING SOURCES}

This work was supported by internal funding from the University of Florida IFAS Research Deans to Stofer, Dunckel, and Krieger. The authors declare no financial conflict of interest.

\section{ACKNOWLEDGMENTS}

The authors wish to thank the staff at the Florida Museum for their assistance with data collection and exhibit preparation.

\section{ABBREVIATIONS}

STEM: Science, Technology, Engineering, Math; STEAM: Science, Technology, Engineering, Art, Math.

\section{REFERENCES}

Alender, B. (2016). Understanding volunteer motivations to participate in citizen science projects: a deeper look at water quality monitoring. JCOM - The Journal of Science Communication. Retrieved from https://jcom.sissa.it/archive/15/03/JCOM_1503_2016_A04

American Association for the Advancement of Science. (2016, November 3). Why Public Engagement Matters. Retrieved January 13, 2017, from AAAS - The World's Largest General Scientific Society website: https://www.aaas.org/pes/ what-public-engagement

Bhattacharyya, R., Templin, E., Messer, C., and Chazdon, S. (2017). Participatory evaluation and learning: A case example involving ripple effects mapping of a tourism assessment program. Journal of Extension, 55(2). Retrieved from https://www.joe.org/joe/2017april/a3.php

Bolsen, T., Druckman, J. N., and Cook, F. L. (2015). Citizens', scientists', and policy advisors' beliefs about global warming. The ANNALS of the American Academy of Political and Social Science, 658(1), 271-295. https://doi. org/10.1177/0002716214558393

Bonney, R., Ballard, H., Jordan, R., McCallie, E., Phillips, T., Shirk, J., and Wilderman, C. C. (2009). Public participation in scientific research: Defining the field and assessing its potential for informal science education. a caise inquiry group report. Online Submission. Retrieved from http://www.eric.ed.gov/ERICWebPortal/detail?accno $=$ ED5 19688

Cameron, F. (2010). Liquid governmentalities, liquid museums and the climate crisis. In F. Cameron and L. Kelly (Eds.), Hot Topics, Public Culture, Museums (pp. 112-128). Newcastle upon Tyne, UK: Cambridge Scholars Publishing.

Carolan, M. S. (2008). The bright-and blind-spots of science: why objective knowledge is not enough to resolve environmental controversies. Critical Sociology, 34(5), 725-740.

Christiano, A., and Neimand, A. (2017, January). Stop raising awareness already (SSIR). Stanford Social Innovation Review. Retrieved from https://ssir.org/articles/entry/stop_ raising_awareness_already

Cook, J., Oreskes, N., Doran, P. T., Anderegg, W. R., Verheggen, B., Maibach, E. W., Carlton, J.S., Lewandowsky, S., Skuce, A.G., and Green, S.A. (2016). Consensus on consensus: a synthesis of consensus estimates on human-caused global warming. Environmental Research Letters, 11(4), 048002.

Creswell, J. W., and Clark, V. L. P. (2007). Designing and Conducting Mixed Methods Research. Retrieved from http://onlinelibrary.wiley.com/doi/10.1111/j.17536405.2007.00097.x/full

Dallas, D. (1999). Science in culture: The cafe scientifique. $\mathrm{Na}$ ture, 399, 120.

Data USA. (n.d.). Retrieved May 8, 2018, from https://datausa.io/ profile/geo/gainesville-fl/\#demographics 
Davies, S. R., McCallie, E., Simonsson, E., Lehr, J. L., and Duensing, S. (2009). Discussing dialogue: perspectives on the value of science dialogue events that do not inform policy. Public Understanding of Science, 18(3), 338-353.

Dijkstra, A. (2017). Analysing Dutch Science Cafés to better understand the science-society relationship. JCOM - The Journal of Science Communication. Retrieved from https:// jcom.sissa.it/archive/16/01/JCOM_1601_2017_A03

Frumkin, H., Hess, J., Luber, G., Malilay, J., and McGeehin, M. (2008). Climate change: The public health response. American Journal of Public Health, 98(3), 435-445. https://doi. org/10.2105/AJPH.2007.119362

Heath, C., Lehn, D. V., and Osborne, J. (2005). Interaction and interactives: collaboration and participation with computer-based exhibits. Public Understanding of Science, 14(1), 91-101. https://doi.org/10.1177/0963662505047343

Hmielowski, J. D., Feldman, L., Myers, T. A., Leiserowitz, A., and Maibach, E. (2014). An attack on science? Media use, trust in scientists, and perceptions of global warming. Public Understanding of Science, 23(7), 866-883.

Hsieh, H.-F., and Shannon, S. E. (2005). Three approaches to qualitative content analysis. Qualitative Health Research, 15(9), 1277-1288.

Jayaratne, K. S. U., Hanula, G., and Crawley, C. (2005). Simple method to evaluate series-type Extension programs. Journal of Extension, 43(2), Article 2TOT3.

Kahan, D. M. (2008). Cultural Cognition as a Conception of the Cultural Theory of Risk (SSRN Scholarly Paper No. ID 1123807). Retrieved from Social Science Research Network website: $\mathrm{http}: / /$ papers.ssrn.com/abstract $=1123807$

Kahan, D. M. (2012). Cognitive Bias and the Constitution of the Liberal Republic of Science (SSRN Scholarly Paper No. ID 2174032). Retrieved from Social Science Research Network website: $\mathrm{http}: / /$ papers.ssrn.com/abstract=2174032

Kamolpattana, S., Chen, G., Sonchaeng, P., Wilkinson, C., Willey, N., and Bultitude, K. (2015). Thai visitors' expectations and experiences of explainer interaction within a science museum context. Public Understanding of Science (Bristol, England), 24(1), 69-85. https://doi. org/10.1177/0963662514525560

Kato-Nitta, N., Maeda, T., Iwahashi, K., and Tachikawa, M. (2017). Understanding the public, the visitors, and the participants in science communication activities. Public Understanding of Science, 0963662517723258. https://doi. org/10.1177/0963662517723258

Lafrenière, D., and Cox, S. M. (2012). Means of knowledge dissemination: Are the Café Scientifique and the artistic performance equally effective? Sociology Mind, 02(02), 191199. https://doi.org/10.4236/sm.2012.22025

Lengwiler, M. (2009). Participatory Approaches in science and technology. Museums and Social Issues, 4(1), 67-82. https://doi.org/10.1179/msi.2009.4.1.67
Lövbrand, E., Pielke, R., and Beck, S. (2011). A democracy paradox in studies of science and technology. Science, Technology and Human Values, 36(4), 474-496. https://doi. org/10.1177/0162243910366154

Lundgren, L., Stofer, K., Dunckel, B., Krieger, J., Lange, M., and James, V. (2019). Panel-based exhibit using participatory design elements may motivate behavior change. Journal of Science Communication, 18(2), A03. https://doi. org/10.22323/2.18020203

McKenzie-Mohr, D. (2013). Fostering Sustainable Behavior: An Introduction to Community-Based Social Marketing. New Society Publishers.

Melillo, J. M., Richmond, T. C., and Yohe, G. W. (2014). Climate Change Impacts in the United States: The Third National Climate Assessment. https://doi.org/10.7930/J0Z31WJ2

Mizumachi, M., Matsuda, K., Kano, K., Kawakami, M., and Kato, K. (2011). Scientists' attitudes toward a dialogue with the public: A study using "science cafes." Journal of Science Communication, 10(4), 1-11.

Moser, S. C. (2007). More bad news: The risk of neglecting emotional responses to climate change information. Retrieved from http://psycnet.apa.org/psycinfo/2007-06263-003

Ordner, J. P. (2017). Community action and climate change. Nature Climate Change, 7(3), 161-163. https://doi.org/10.1038/ nclimate 3236

Pew Research Center. (2015a). Americans, Politics and Science Issues. Washington, DC.

Pew Research Center. (2015b). Public and Scientists' Views on Science and Society. Retrieved from http://www.pewinternet.org/2015/01/29/public-and-scientists-views-on-science-and-society/

Popovich, N., Schwartz, J., and Schlossberg, T. (2017, March 21). How Americans Think About Climate Change, in Six Maps. The New York Times. Retrieved from https://www. nytimes.com/interactive/2017/03/21/climate/how-americans-think-about-climate-change-in-six-maps.html

Public Praises Science; Scientists Fault Public, Media. (2009, July 9). Retrieved March 1, 2014, from Pew Research Center for the People and the Press website: http://www. people-press.org/2009/07/09/public-praises-science-scientists-fault-public-media/

Rai, K. (2003). Broadening and deepening the definition of outreach scholarship: Linking Popular education and community-based participatory action research. Journal of Higher Education Outreach and Engagement, 8(1), 113-126.

Saldaña, J. (2016). The coding manual for qualitative researchers (3E [Third edition]). Los Angeles ; London: SAGE.

Scharrer, L., Rupieper, Y., Stadtler, M., and Bromme, R. (2016). When science becomes too easy: Science popularization inclines laypeople to underrate their dependence on experts. Public Understanding of Science, 0963662516680311. https://doi.org/10.1177/0963662516680311 
Seidman, I. (2013). Interviewing as qualitative research: a guide for researchers in education and the social sciences (4th ed). New York: Teachers College Press.

Simon, N. (2010). The participatory museum. Santa Cruz, California: Museum 2.0.

Stofer, K. A. (2015). Informal, non(-)formal, or free-choice education and learning? Toward a common terminology for agriscience and Ag-STEM educators. Journal of Human Sciences and Extension, 3(1), 125-134.

The Nielsen Company. (2014). Nielsen Station Index: Viewers in Profile [Diary Service].

van der Linden, S. L., Leiserowitz, A. A., Feinberg, G. D., and Maibach, E. W. (2015). The scientific consensus on climate change as a gateway belief: Experimental evidence. PLOS ONE, 10(2), e0118489. https://doi.org/10.1371/ journal.pone.0118489

Volmert, A., Baran, M., Kendall-Taylor, N., Lindland, E., Haydon, A., Arvizu, S., and Bunten, A. (2013). "Just the Earth Doing Its Own Thing”: Mapping the Gaps Between Expert and Public Understandings of Oceans and Climate Change [A FrameWorks Research Report]. Washington, DC: FrameWorks Institute.

Volmert, A., Baran, M., Kendall-Taylor, N., and O’Neil, M. (2013). "You Have to Have the Basics Down Really Well": Mapping the Gaps Between Expert and Public Understandings of STEM Learning [A FrameWorks Research Report]. Washington, DC: FrameWorks Institute. 